\title{
POWER DEPENDENCE IN INDIVIDUAL BARGAINING: THE EXPECTED UTILITY OF INFLUENCE
}

\author{
EDWARD J. LAWLER and SAMUEL B. BACHARACH
}

$\mathbf{E}$ VFRYDAY life is full of mixed-motive settings in which individuals must decide whether to attempt to influence others. The decision process in such situations is complicated by the fact that any influence attempt can have either of two opposite ef. fects: it may overcome the resistance of the adversary and facilitate the actor's goal attainment or it may antagonize the adversary and impede the goal attainment of the actor. Deciding whether to attempt influ.

This study examines the imusect of certain dimesssioms of dependence on the expected elfectiveness of an influ(unce attempu in a (wo)-person bargaining situa(ion. Assuming the role of entoloyer, employec, or ontside observer, 1,056 college students t'stimated the Itility of atm altempt by all employes to influenec his (eny)loyer willy respece to a pay raise under various conditions of dependence. J'he results show ilsat respoudents attributed greatest tuility to llye altempr when the (moloyec lad matly alternatives (other job possibilitics) and walued highly the outcomes at issue (a pay raise) and when lhe employer lond few allematives (other workers) and ascribed lew value to the outcounes. The authors finel that the power-eapability liyjolheses derived frou power-dependence theory are suppored by the two oucone-alternative dimensions but not by the wo outcome-yalue dimensions. 'The latter are found to support commituent hypotleses.

Edward J, lawler is Associate l'yofessor of Socjology in 'Ihe University of lowa and Samucl 3. Bacharach is Associatc Prolessor of Organizational Behavior at the New York State School of Industrial and I abor Relations. 'The order of authorship of this panjer does not reflect differential contributions; it las been a irtly joint endenvor. The autluors would like to thank Stuatt Jireceloutu, Latry Fatfince, Stuart Stever, and l'an Kline for assistance in the dati collection and analysis. - Emror ence therefore becomes a major dilemma for anyone who is in conflict or disagreement with an employer, spouse, neighbor, ally, or even enemy. This study is concerned with how actors "cognitively" handle this dilemma, that is, how they use situational cues to judge the expected utility of an influence attempt in a situation of conflict or disagree. ment. 'Specifically, the research investigates the processes through which actors select and use information about a bargaining situation, involving an employer and an employee, to estimate the magnitude and probability of payoff from an influence attempt.

The cognitive focus of this research distinguishes it from most social psychological research on conflict. Such research typically adopts a behavioral focus and neglects the cognitive processes underlying the behavior. While there obviously are good reasons for a behavioral focus, it has led to some rather glaring gaps in the existing literature and made the application of experimental research to the real world more problematic than it need be. Treatments of expected utility are a notable example. At this point, we know that expected utility affects a variety of behavior (such as coalition formation and compliance), but we know very

\footnotetext{
"The tern "cognition" refers to the mental activity through which individuals interpret or come to understand a situation. The term, appliexl to estimated utility in the present study, refers to llie mental activity that intervenes between situational cues or information and an individual's sulssecjucnt behavior.
} 
little about how actors use situational or informational cues to estimate expected utility. The importance of this gap becomes clearer if we compare laboratory settings for studying utility with "real world" settings. In most laboratory experiments, actors are given concrete, relatively perfect information on the utility attached to a behavior, and the rate or frequency of their behavior is then observed. ${ }^{2}$ Such experiments provide valuable information on the behavioral effects of utility but no information on how individuals might use incomplete or am. biguous information about a situation to form estimates of utility.

In the "real world" actors seldom have complete or perfect information upon which to estimate the utility of an influence attempt; they must infer utilities from incomplete, ambiguous information regarding any bargaining situation and must, therefore, rely heavily on cognitive judg. ments to assimilate and syncretize the utilitarian implications of available informa. tion. Consequently, to apply laboratory research on the effects of utility to the "real world," we must understand more than the effects of utility on behavior; we must also understand how actors appraise various aspects of a bargaining situation to form utility estimates.

This study uses power-dependence theory as a framework for examining whether and how parties use information on each other's dependence to estimate the utility of an influence attempt. ${ }^{3}$ The effect of dependence on expected utilities is investigated in an employee-employer context in which the employee (or potential influencer) is deciding whether to pressure the employer (or

2S. Lymne Orshe and Richard J, Orshe, Utility and Choice in Social Interaction (Englewood Cliffs, N.J.: Prentice-Hall, 1970), P12. 2l-90; Jantes T. 'Tedeschi, Thomas V. Bonoma, and Barry R. Schlenker, "Influence, Decision, and Compliance," in J. ' $\mathrm{T}$. 'Tedeschi, ed., Social Influence Processes (Chicago: AldineAtherton, 1972), pp. 346-404; Sidney Siegel, Choice, Strategy, and Uility (New York: McGraw.Hill, [964); Richard E. Walton and Robert B. Mckersic, A Behavioral Theory of Labor Negotiations (New York: McGraw-Hill Book Co., I965).

"Robert M. Emerson, "Social Exchange "Theory," Annual Review of Sociology, Vol. 2(1976), p). \$35.62; Peter Blau, Exchange and Power in Social Life (New York: Wiley, 1964), 1pp. 115-25. potential target of influence) for a pay raise. Within this context, power-dependence theory provides a backdrop for specilying the impact of various dimensions of dependence on the (subjective) expected utility of an employee influence attempt. Before discussing power-dependence theory, we will use decision theory to conceptualize "utility," the dependent variable.

Based on decision theory, the simplest and most generally accepted definition of expected utility is the magnitude of outcomes expected to result from certain behavior weighted by the expected probability that those outcomes will result from the behavior (magnitude $x$ probability). ${ }^{4}$ From this central idea a number of variants have been developed incorporating additional aspects of expected utility. For example, in addition to the magnitude and probability variables, Ofshe and Ofshe include equity as an aspect of utility and Siegel adds behavior variability (avoidance of boredom). ${ }^{5}$ The present research focuses solely on the central idea: magnitude $x$ probability.

The implication of decision theory is that outcome magnitude and probability are the foci of the actor's utility judgments. 'That is, actors' impressions of and inferences regarding the bargaining situation should be summarized, transformed, and crystallized into overall estimates of the outcome probability and outcome mag. nitude that would result from an influence attempt. With reference to the present study, therefore, the expected utility of an influence attempt lies not in the perceived magnitude of the prospective pay raise alone but in the product of the anticipated magnitude and anticipated probability of a pay raise. Unlike research that gives actors the magnitude and probability levels and

\footnotetext{
Orshe and Orshe, Utitity and Choice in Social Interaction, pp. 21-30; Sicgcl, Choice, Strategy, and Utility, pp. 9-10; Tedeschi, Bonoma, and Scliletsker, "Inlluence, Decision, and Compliance"; Anthony Heath, Rational Choice and Social Exchange (New York: Cambridge University Press, 1976), pp. 19-14; Gedwin C. Chu, "Fent Arousal, Eflicacy, and Imminency," Journal of Personality and Social Psychol. ogy, Vol. 4, No. 5 (November 1966), pp. 517-24.

SOfshe and Ofshe, Utility and Choice in Social Imteraction, pp. 21-30; Sidney Sicgel, Choice, Strategy, and Utility, pp. 9-10.
} 
then observes their behavior, the present research examines the situational cues from which individuals infer probability and magnitude levels.

\section{Power-Dependence Theory}

Power-dependence theory is a useful basis for analyzing the process through which actors estimate the utility of an influence attempt. Although the theory does not contain explicit statements regarding this process, implications regarding the effects of dependence can be drawn from it. With the use of axioms, this paper will elaborate and systematize the implications of powerdependence theory.

Jirst, power-dependence theory identifies the major dimensions of dependence as outcome alternatives and value. Alternatives refer to the availability of outcomes from other relationships, and value to the "importance of" or "necd for" the outcomes in question. ${ }^{6}$ Applied to the employeeemployer context, there are two alternative dimensions (alternative jobs for the em. ployee and alternative workers for the employer) and two value dimensions (the importance of a pay raise to the employee and the importance to the employer of avoiding a pay raise).

In addition, the theory suggests that actors will use the dimensions of dependence to estimate each other's power capability (potential power). Specifically, the employee's power capability will be perceived as greater (and the employer's as lower) when the employer has few alternatives or highly values the outcomes at issue, and the employee has many alternatives or ascribes low value to the outcomes at stake. These implications of power-dependence theory for the perception of power are supported in a recent study? Bacharach and

6Robert M. Enerson, "Exchange l'heory Part I: $\Lambda$ Psychological Basis for Social Exchange," in Joseyjh Berger, Morris Zelditch, and Bo Anderson (eds.), Sociological Theories in Progress, Vol. 2 (Boslon: Houghton Mifflin, 1972), 1p). 38-57; Blau, Exchange and Power in Social Life, $\mathrm{pp}$. $115-25$; John W. Thibaut and Harold H. Kelley. The Social Psychology of Groups (New York: Wiley, 1950), |p|). 100-01.

"Simuel H. Bacharach and Edwatd J. Lawler, "The Petception of Power," Social forces, Vol. 55, No. 3 (Seplember 1976), pp. I28-34.
Lawler observed that a person in the employee position uses the dimensions of dependence to infer self's and other's (employer) power capability in a manner consistent with power-dependence theory.

The results of the Bacharach and Lawler strdy of power perceptions can be subsumed under a single axiom, which provides a starting point for predicting the effects of dependence on the perception of utility:

Axiom 1: If Employee's dependence on Employer decreases (or Employer's dependence on Employee increases), then the power capability attributed to Employee will increase and the power capability attributed to Employer will decrease.

To deduce predictions regarding expected utilities, however, it is necessary to postulate a relationship between attributed power capabilities and the perceived utility of an influence attempt. Such a postulate is reasonable because various studies document the fact that influence attempts are generally more effective when they are buttressed by high-power capabilities. ${ }^{g}$ Keeping the cognitive focus of the present research in mind, Axiom 2 suggests that actors will perceive such a connection betwcen power capabilities and the utility of an influence attempt.

Axiom 2: If there is an increase in the power capability attributed to Employee (or a decrease in the power capability attributed to Employer), then there will be an increase in the subjective expected utility of an Employee inlluence attempt.

This research focuses on a theorem derived from these two axioms, which suggests that a change in any of the alternative or value dimensions of dependence will produce a corresponding change in the utility attributed to an influence attempt:

Theorem: If Employee's dependence on Employer decreases (or Employer's dependence on Employee increases),

BJeffrey A, Rubin ankl Bert Brown, The Social Psychology of Bargaining and Negotiation (New York: Academic Press, 1975), pp. 213.21. 
then there will be an increase in the subjective expected utility of an Employee influence attempt.

Four specific hypotheses based on this theorem will be tested in this research. The expected utility of an employee's influence attempt will be greater (1) when the employee has many rather than few alterna. tives (decrease in employee's dependence), (2) when the employer has few rather than many alternatives (increase in employer's dependence), (3) when the employee ascribes low rather than high value (importance) to the outcomes at issue (decrease in employec's dependence), and (4) when the employer ascribes high rather than low value (inportance) to the outcomes at issue (increase in employer's dependence). These four hypotheses are based on the powercapability rationale; they assume that individuals will make power-capability inferences from the dimensions of dependence and use these inferences to estimate the utility of an influence attempt.

Although research documents that individuals make power-capability inferences from information on outcome value and alematives, ${ }^{9}$ it is atso possible that they consider the attitudinal commitment of an actor to the outcomes at stake. For example, individuals might infer that an employce who highly values the outcomes at stake will be very committed to influencing the employer and that an employer who highly values the outcomes will be very committed to resisting influence attempts by the employce. Thus, either the power-capability or commitment implications of outcome value could be used to estimate the utility of an influence attempt.

The direction of the outcome-value effects on the utility expectation will depend on the relative weight given the powercapability and commitment implications of information on outcome value. If the power-capability implications are accorded the greater weight, then the research should support hypotheses 3 and 4. If, on the other hand, the commitment implications of outcome value are judged more salient, then

sBacharach and Lawler, "The P'erception of Power." the effects of outcome value on expected utility slould be the reverse of hypotheses 3 and 4: greater utility should be attributed to an influence attempt when the em. ployee's value is high instead of low and when the employer's value is low instead of high. These contradictory hypotheses are plausible because actors who are highly committed (high value) to the outcomes at stake might be expected to invest greater resources (such as time and effort) to combat the opponents' resistance. An employee with high value may invest more resources to gain a pay raise, and the employer with high value may invest more resources to block a pay raise. It is our intention to determine whether the power-capability or commitment implications of outcome value are more important in individuals' predictions of the utility of an influence attempt.

\section{Method}

A role-playing method was used to manipulate the four dependence dimensions: employee's alternatives (jobs), employee's value, employer's alternatives (workers), and employer's value. ${ }^{10}$ These four variables

\footnotetext{
10 Mllhough this method contains substantial artificiality, like that encountered in lalsotatory studies, it has a number of advantages over laboratory studies for resentch in perception or cognition. First, a larger number of subjects and a larger experimental design can be employed with a questionnaire without mach loss of experimental control. Second, despite the artificialiny, the major elements of "real world" scllings can still be built into the role-playing setting. Just as prople in everyday setlings use information aluout the situation to make inferences about themselves and others, so do the subjects in our experiment. The "information processing" present in the real world is nlso present in our experiment. The difference is that we lave selectext certain aspects of the situation and certain inferences to isolate and examinc in our experimental setting.

One of the major problems with a role-playing nucthod is that subjects may difler in the amount of experietuce they have had in the context portrayed within the sludy. We would expect most subjects (college students) to have some exjerience (direct or vicarious) with conployce-employer situations, but the type and degrec of experience could vary across subjects. As long as one randomly assigns subjects to experimental conditions, however, such differential experience could not account for significant differ. ences among the experimental conditions. In fact, the variance in subjects' cognitions that is due to dilfer.
} 
were manipulated as high versus low in a $2 \times 2 \times 2 \times 2$ factorial design. A total of 1,056 students from two Northeastern universities were randomly assigned to one of the 16 experimental trealments. The roles of the respondents (perceivers) were counterbalanced within experimental conditions. One-third of the respondents within each experimental condition took the role of the employee, one-third took the role of the employer, and one-third took the role of a third party olsserving the employer-employee altercation. Across these role standpoints, respondents estimated the utility of an employee influence attempt (the perceived probability and magnitude of a pay raise resulting from an influence attempt). This role counterbalance assures that any effects of dependence cannot be attributed to a particular role and enables a test for interactions by role. The presentation of the procedures and results places the reader in the observer position. The only difference among the role conditions was in the words used to refer to persons in each role.

The procedurcs called for respondents to read a description of a hypothetical situation and then to complete a questionnaire. The description portrayed an employee. employer conflict over pay raises. The $\mathrm{cm}$ ployer (manager-owner of a clothing store), who bad not recently given pay raises to the employees (salespersons), was in the process of deciding whether to allot increases through commissions. Respondents were told that the employer was currently leaning against raises but would make the finat decision about two weeks hence. Understanding that it would be impossible to clange the employer's mind once the pay. raise decision were made, the employee was faced with deciding whether to at lempe 10 influence his employer in the interim period. Within this context, respondents (in employee, employer, or observer role) were asked to estimate the utility of an $\mathrm{cm}$. ployee influence attempt.

The description of the situation also contained information manipulating the

ential experience with comparable "real worlel" silualtions should reduce the probubitity of finding significant effects for the namipulated variables. tour dependence dimensions. The availability of alternative jobs for the employee and alternative workers for the employer manipulated the two outcome-alternative dimensions. Specifically, the employee's alternatives manipulation stated: "The job market for salespersons, like the employee (you), is very poor (very good), and there is only a $10 \%$ (a $90 \%$ ) chance that the employee (you) could find a better job." The manipuJation of the employer's alternatives stated: "The employer (you) would find it difficult (easy) to replace the employee (you) because there is only a $10 \%$ (a $90 \%$ ) chance that the employer (you) could hire another person with the employee's (your) qualifications."

Outcome value was manipulated by varying the importance of getling pay raises (for employees) or avoiding pay raises (for employers). Specifically, the employee's value manipulation stated: "A pay raise is not at all important (very important) to the employee because the employee's (your) financial situation has greally improved (seriously deteriorated) in the last year. Similarly, the employer's value was manipulated by the following statement: "It is not at all important (very important) that the employer (you) avoid pay raises because the store's financial situation was greatly improved (seriously deteriorated) in the last year." Thus, both the employee and the employer had information on each other's dependence situation.

\section{Dependent Variable}

A questionnaite, containing the dependence measures, followed the description of the situation. Respondents were instructed to read the hypothetical situation twice before procceding to the questionnaire. (This process was intended to equalize respondents' understanding of the situation and reduce any differences in understanding duc to reading-comprehension ability.) Respondents were told that these were no riglit or wrong answers on the questionnaire, and that the research was only concerned with their personal opinions.

The measure of utility expectation was derived from respondents' estimate of the probability and magnitude of a pay raise. The perceived probability of a pay raise, 
given an influence attempt (Prob)Infl), was measured by the following item: "If the employee tries (you try) to influence the employer (you), how likely is it that the employer (you) will give the employee (you) a pay raise?" Subjects responded on a ninepoint scale labeled "not at all likely" at the low end and "highly likely" at the high end. The perceived magnitude of the pay raise, given an influence attempt (MagInfl), was based on an item stating, "If the employee tries (you try) to influence the employer (you), and the employer gives (you give) a pay raise to the employee (you), how large or small would you expect the pay raise to be?" Subjects responded on a nine-point scale labeled "very small" at the low end and "very large" at the high end. The expected utility of influence was measured by multiplying the probability and magnitude estimates: $u t i l i t y=($ Problinll $) \times($ Maglnfl $)$.

To assure ourselves that respondents understood the description of the situation, an ancillary questionnaire item was included inquiring how easy or difficult it was to understand. Respondents answered on a nine-point scale with higher numbers reflecting greater understanding. They reported considerable understanding of the situation: across experimental conditions, the mean level was 7.0 on the nine-point scale.

\section{Resulis}

The hypotheses stated earlier make predictions regarding the effect of each dependence dimension on the expected utility of an influence attempt. After detailing the major effects lound, we will examine ancillary results regarding the effects of the respondents' role and sex.

The table presents the mean values for expected utility by experimental condition. $A$ five-way analysis of variance $(2 \times 2 \times 2 \times 2$ $x 3$, including role) reveals a main effect for each dependence dimension and an interaction eflect between the two outcomealternative dimensions. The main effects of the two outcome-alternative dimensions are consistent with the power-capability hypotheses: the expected utility was greater when the employee had many, rather than few, alternatives $(F(1,1008)=26.94, p<.01$; $\left.w^{2}=.023\right)$ and when the employer had lew, rather than many, alternatives $(F(1,1008)$ $\left.=58.13, p<.001 ; w^{2}=.05\right)$. An interaction effect shows, however, that the effect of the two outcome-alternative dimensions is multiplicative rather than additive $\left(F(1,1008)=26.94, p<.001 ; w^{2}=.023\right)$. Post-hoc (pairwise) comparisons, using Tukey's HSD (Honestly Significant Difference), reveal that the expected utility was higher in the high employee alternatives. low employer alternatives condition than in

Table. The (Subjective) Expected Utility of an Influence Attempt by Dimensions of Dependence.

\begin{tabular}{|c|c|c|c|c|}
\hline \multirow[t]{3}{*}{ Euryjloyer } & \multicolumn{4}{|c|}{ Eimployee } \\
\hline & \multicolumn{2}{|c|}{ Low Value } & \multicolumn{2}{|c|}{ High Value } \\
\hline & $\begin{array}{c}\text { Low } \\
\text { Mltcrnatives }\end{array}$ & $\begin{array}{l}\text { High } \\
\text { Alıernatives }\end{array}$ & $\begin{array}{c}\text { Low } \\
\text { Altemnatives }\end{array}$ & $\begin{array}{c}\text { High } \\
\text { Alternatives }\end{array}$ \\
\hline \multicolumn{5}{|l|}{ Low Value } \\
\hline $\begin{array}{l}\text { Low Alkrmatives } \\
\text { Higl Alternatives }\end{array}$ & $\begin{array}{l}19.94 \\
17.58\end{array}$ & $\begin{array}{l}28.69 \\
19,61\end{array}$ & $\begin{array}{l}23.91 \\
22.26\end{array}$ & $\begin{array}{l}29.12 \\
21.95\end{array}$ \\
\hline \multicolumn{5}{|l|}{ High Value } \\
\hline $\begin{array}{l}\text { Low Altermatives } \\
\text { High Alternatives }\end{array}$ & $\begin{array}{l}1 \$ .67 \\
11.50\end{array}$ & $\begin{array}{l}19.41 \\
10.02\end{array}$ & $\begin{array}{l}15.36 \\
15.09\end{array}$ & $\begin{array}{l}23.77 \\
14.80\end{array}$ \\
\hline
\end{tabular}

\footnotetext{
"Larger number means higher expecexd utility.
} 
any of the other conditions (all p's $<.01$ ). In other words, the expected utility of an employee influence attempt was highest when the employee had many alternatives and the employer had lew. In sum, the results for outcome alternatives support a refined version of the hypotheses drawn from power-dependence theory.

The main effects for the two outcomevalue dimensions support the commitment rather than the power-capability lyypotheses. 'The utility of an influence attempt was greater' when the employee attached high rather than low value to the outcomes at issue $\left(F(1,1008)=22.97, p<.001 ; w^{2}=\right.$ ,02); and the expected utility was greater when the employer accorded low rather lisan high value to the outcomes $(\mathrm{F}(1,1008=$ $121.13, p<.001 ; w^{2}=.11$ ). 'There were no interactions. Individuals apparently infer an actor's commitment to expend resources from their perception of the actor's outcome value and then adjust their evaluation of utilities accordingly.

The expected-utility measure multiplies respondents ${ }^{t}$ estimates of probability and magnitude. It is possible, therefore, that an effect on either perceived probability or perceived magisitude could produce the foregoing effects. To examine this possi. bility, separate analyses of variance were done on the perceived probability and perceived magnitude of a pay raise. The results indicated that each dimension of dependence affected both the perceived probability and perceived magnitude of the pay raise associated with influence (all p's < .001) in a manner consistent with the aforementioned findings.

Respondents estimated the utility of an employee influence attempt from one of the following standpoints: the employee, the employer, or an observer. The results show a role main effect indicating that persons in the observer role attributed somewhat less utility to an employee influence attempt than persons in either the employee or employer role $(F(I, 1008)=12.84, p<.001$; $w^{2}=.02(M s=16.9$ for observer, 19.5 for employee, and 21.1 for employer)). Observ. ers, who are without a stake in the employeeemployer conflict, are apparently less optimistic about the effectiveness of influence than persons more directly involved in the conflict.

In addition to the role main effect, a few interactions by role occur. These interactions do not alter or limit the effects of the dependence dimensions, and together they add less than a total of 2 percent to the variance explained. It appears that respondents in different roles used the dimensions of dependence in a similar manner to estimate the utility of an employee influence attempt.

An analysis of variance including the respondents' sex as a factor reveals no main effects or by-sex interactions. Hence, males and lemales used the dimensions of dependence similarly to make judgments.

\section{Discussion}

The central theoretical contribution of this study is to the power-dependence literature. The importance of cognition in conflict settings requires documentation of how individuals use the "objective" features of the environment 10 "define the situation." If it can be shown that people use the "objective" criteria of dependence to make cognitive judgments that are important to conflict behavior, then the potential value of power-dependence theory should be enhanced. This research affirms respondents' use of dependence dimensions to estimate utilities but also demonstrates that the direction of the effects is not fully consistent with the power-capability hypotheses detived from power-dependence theory.

$\Lambda$ prior study with similar research procedures indicates that actors use the dimensions of dependence to estimate power capabilities in a manner consistent with the theory." Given that the dependence dimensions reveal the predicted effects (Axiom I) on perceptions of power capabilities, one would also expect to confirm the power. capability hypotheses regarding (subjective) expected utilities. A change in the dependence of either actor would presumably engender similar effects on both powercapability estimates and attributions of utility to an influence attempt. However,

\footnotetext{
"Bacharach and Lawler, "The Pecepption of Power."
} 
while the results show that respondents use all four dimensions of dependence to make utility estimates, only partial support is accorded the specific predictions of powerdependence theory.

In the case of the two outcome-alternative dimensions, the results support the theory but suggest a multiplicative rather than an additive effect. Specifically, the expected utility of an employee influence attempt increases only when the employee has many alternatives and the employer has few alternatives. Overall, the interaction of the two outcome-alternative dimensions suggests that respondents consider two conditions necessary for successful influence in an employee-employer situation: (a) the influencer (employee) must be able to leave the relationship, perhaps avoiding retaliation or punishment, and (b) the target of influence (employer) must not be able to leave the relationship without cost. According to power-dependence theory, these two conditions provide the maximum power advantage to the employee.

Furthermore, the two conditions have important tactical implications. The tactic of cultivating more alternatives will not enhance the perceived influence of an employee if the employer has many alternatives. The respondents indicated that an expectation of successful influence requires simultaneous increases in the employee alternatives and decreases in the employer alternatives. Given that collective action is often necessary to alter the employer's alternatives, the interaction between the outcome-alternative dimensions appears to provide one basis for employee efforts to organize rather than rely on individual action.

While the effects of the outcome alternative dimensions support a refined or more specified version of power-dependence theory, the results for outcome-value dimensions are consistent with the commitment hypotheses rather than the power-capability (power-dependence) ones. Specifically, respondents attribute greater probabilities and magnitudes of pay to an influence attempt when the influencer (employee) values the outcomes at issue highly or when the target of influence (employer) ascribes them low value. This is important because it suggests that different dimensions of dependence may have different implications for actors in a conflict setting.

Results supporting the commitment hypotheses suggest that an actor (either influencer or target of influence) is confronted with an important dilemma if the opponent highly values the outcomes at issue. One the one hand, the ability of the actor to effect outcomes highly valued by the opponent should provide a base (power capability) for maximizing influence; ${ }^{12}$ on the other hand, the actor might anticipate an increase in the opponent's commitment to achieve or block influence when highly valued outcomes are involved. ${ }^{13}$ The manner in which this dilemma is resolved will determine the nature of the outcome-value effect on expected utilities in a conflict setting, The present study indicates that actors give greater weight to the commitment implications of outcome value than to the power-dependence ones when estimating the utility of an influence attempt.

Future research should further specify the conditions under which actors draw different inferences from outcome-alternative and outcome-value dimensions. The fact that there are often multiple outcomes at stake in a conflict situation raises some important questions. For example, will the inferences (power-capability versus commitment) depend on the centrality of the outcomes to the conflict? In the present study, only one outcome continuum (pay) was included, and it was the central focus of the conflict. It is conceivable that commitment inferences will be drawn primarily from information on outcomes that are central to the altercation because these outcomes are the major source of the conflict. Other outcomes,

\footnotetext{
"Emerson, "Power-Dephntence Relations," and "Exchange Theory Part I"; Bacharach and Lawler, "Perception of Power."

13Ediward J. Lawler and Sanumel B. Bacharach, "Outcome Alternatives and Value As Criteria for Multitactic Evaluations," Journal of Personality and Social Psychology, Vol. 34, No. 5 (November 1976), pp. B85.94; Samuel B. Bacharach and Edward J. Law. ler, "Subjective Prediction of Behavior in a Conflict Seting: A Power-Dependence Approach," unpub. lished manuscript.
} 
highly valued but less central to the conflict, may be viewed as a source of power and reveal the power-capability effects on ex. pected utility. That is, other outcomes valued by the opponent may be seen as a means to influence the opponent's stance on the central ones at stake in the conflict. Thus, information on different (independent) outcome continua may have somewhat different effects on the expected utility of an influence attempt.

Given the existence of these multipleoutcome continua, however, it is also important to ask how individuals will weigh and combine dependence information on these disparate outcomes to arrive at overall utility estimates. One possibility is that they will weigh information on the most central outcomes more heavily than that on less central ones. If so, information on different outcome continua could have divergent implications (power-capability versus commitment), but overall utility juclgments may primarily reflect information on the most central ones, suggesting results like those found in this research. These issues should be addressed in future research.

To summarize, this research demonstrates that actors use the dimensions of dependence specified by power-dependence theory to estimate the expected utility of an influence attempt in an individual bargaining situation. On a more general level, the effects suggest that power-capability and commitment are important aspects of the process through which individuals synthesize situational cues and use these cues to estimate utilities. Future research, aside from pursuing the effects of dependence, should identify other situational cues that bear on actors' power-capability and commitment inferences. These inferences and their relation to (subjective) expected utilities are not inextricably bound up with the dimensions of dependence. Any aspect of the bargaining situation (such as level of conflict, interpersonal demeanor, or threat capabilities) that individuals use to infer power capabilities or commitment should have a similar effect on the estimated utility of an influence attempt. In closing, it should be noted that the examination of the effect of power dependence on the estimates of expected utility is only one step in a needed integration between power-dependence theory and the tactics of bargaining. 